\title{
Physical components and influence factors of municipal solid waste (MSW) in the residential area of Beijing
}

\author{
Zhang Hongyu ${ }^{1}$, Wang Guiqin ${ }^{1 *}$, Bai Yaxuan ${ }^{2}$, Chen Rihui ${ }^{1}$ and Zhang Li $^{1}$ \\ ${ }^{1}$ Beijing Municipal Institute of City Management/Beijing Key Laboratory of Municipal Solid Wastes Testing Analysis and Evaluation, \\ Beijing 100028, China \\ ${ }^{2}$ Beijing Institute of Petrochemical Technology, Beijing 102600, China
}

\begin{abstract}
The treatment, disposal and management of municipal solid waste strongly depend on the composition and characteristics of municipal solid waste. The Physical composition of MSW and its influencing factors were investigated and analyzed in the residential of Beijing area. The result showed that the composition of MSW in four seasons was similar, and the kitchen was the main composition of MSW, accounting for $69-74 \%$ of the total amount of MSW. The average age of families, educational backgrounds, family income and building area have a great influence on the physical proportion of MSW. As the average age of the family increases, the proportion of other wastes was gradually reduced, the proportion of the harmful waste was increased. With the increase of educational backgrounds and family income, the content of kitchen waste decreased, while the content of recyclable waste increased obviously. The 50 square meters was used as a dividing point for the residential area of the family, the kitchen waste decreased at first and then increased, while the proportion of disposable packaging and other waste increases at first and then decreases with the increase of building area.
\end{abstract}

\section{Introduction}

MSW is a mixture of many kinds of wastes and a misplaced resource [1-2]. The treatment, disposal and management of municipal solid waste strongly depend on the composition and characteristics of municipal solid waste [3-4]. By analyzing the physical composition of MSW, we can know the content of each component more accurately and estimate the recoverable amount of the material. Natural environment, climate conditions, living habits, fuel structure and other factors affect the composition of municipal solid waste components, so when these factors change or change some external conditions, some physical and chemical characteristics of municipal solid waste will also change [5-7]. Therefore, it is very important for the management of MSW to study the physical composition and clarify the main factors affecting its physical composition. It is not only helpful to formulate the scheme of MSW classification and collection, but also helpful to the selection of MSW treatment methods, the design of equipment and the proposal of new treatment technology [8-11].

At present, there are relatively few studies on the composition characteristics of municipal solid waste in Beijing residential areas. Especially in the recent three years, under the new situation of rapid development of renewable resources reflux and express service industry, the composition of MSW had not been reported. The factors that affect the physical composition of the MSW are not clear in the residential area of Beijing.
In this study, the physical compositions of the MSW were investigated and analyzed in the residential of Beijing area. The factors affecting the physical composition of MSW were also analyzed. This study can provide the technical data for the reduction, harmless and resource recovery of MSW in Beijing.

\section{Materials and methods}

The MSW were collected directly from the family households. The 864 households were selected in the demonstration area of MSW classification in all districts of Beijing. The MSW samples were collected 3 times a month per household, including two days of the week and one day of the weekend. Meanwhile, the average age, building area, educational background and income level of households collecting MSW samples were investigated. The whole investigation lasted for a year. All MSW samples were classified manually as kitchen waste, recyclable, disposable packaging, hazardous waste and other waste. After the MSW classification work was completed, the proportion of different types of waste was calculated according to the following formula 1 .

$$
p_{\mathrm{i}}=w_{\mathrm{i}} / w_{\mathrm{a} \times 100}
$$

$p_{\mathrm{i}}$ refers to the proportion of type $\mathrm{i}$ waste components. $w_{\mathrm{i}}$ refers to the weight of type i waste after classification. $W_{\text {a }}$ refers to the weight of mixed MSW before classification. 


\section{Results and discussion}

\subsection{The effect of seasonal variation on the components of MSW}

The physical compositions of MSW in different seasons were shown in Fig 1. The composition of MSW in four seasons was very similar. It was clear to see that the percentage of kitchen waste was obviously higher than other components. Except for autumn, the average content of kitchen waste was above $70 \%$ in spring, summer and winter. The content of kitchen waste in these three seasons was $2 \%$ higher than that in autumn.

The proportion of other waste in the four seasons of MSW was between 10 and 20 percent, ranking the second place. The proportions of recyclable and disposable packaging of MSW were accounted for $6-8 \%$ and $9-10 \%$, respectively. The main components of recyclable materials were paper products and glass, which together amount to up to $57-68 \%$. The main components of disposable packaging were plastic and glass, which together amount to up to $86-92 \%$. The proportion of harmful waste in MSW was the smallest, less than $1 \%$.

The physical composition of domestic waste in residential areas of Beijing and Shanghai was obviously different. The content of kitchen waste in Shanghai was about 55\%. Rubber and plastic were the second largest component, accounting for $21 \%$, followed by paper, accounting for $13 \%$. The content of other waste components was relatively low, less than $5 \%$.

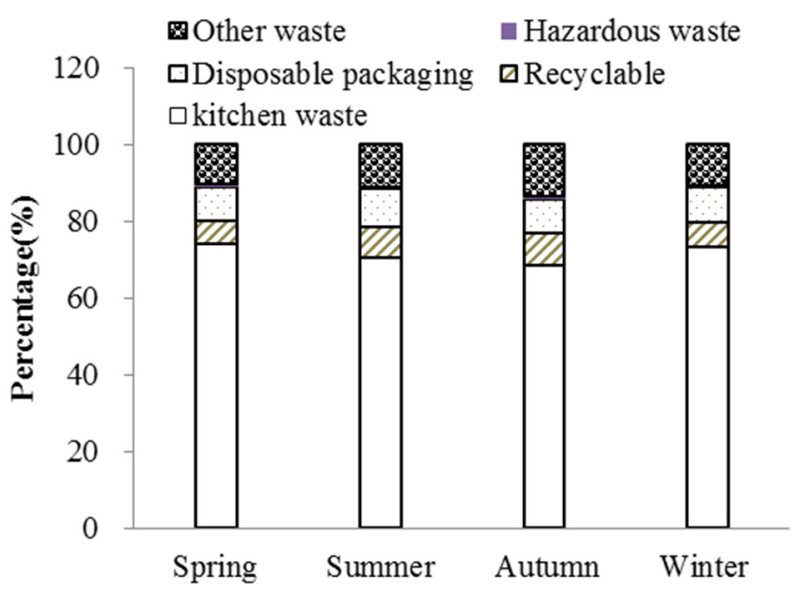

Fig.1. Physical composition of MSW in different seasons

\subsection{The effect of average age of the family on the components of MSW}

The Fig.2 showed the physical composition of MSW in different ages of families. The average age of families had a great influence on the proportion of harmful waste and other waste in MSW. As the average age of the family increased, the proportion of other wastes was gradually reduced, and the proportion of the harmful waste was increased. The harmful waste mainly takes the medicine as the main, accounting for more than $46 \%$ of the total amount of the harmful waste. Therefore, with the aging of the population, the production of MSW in residential areas will increase. In some old and old neighborhoods where the elderly live mainly, the construction of supporting facilities for MSW should be increased.

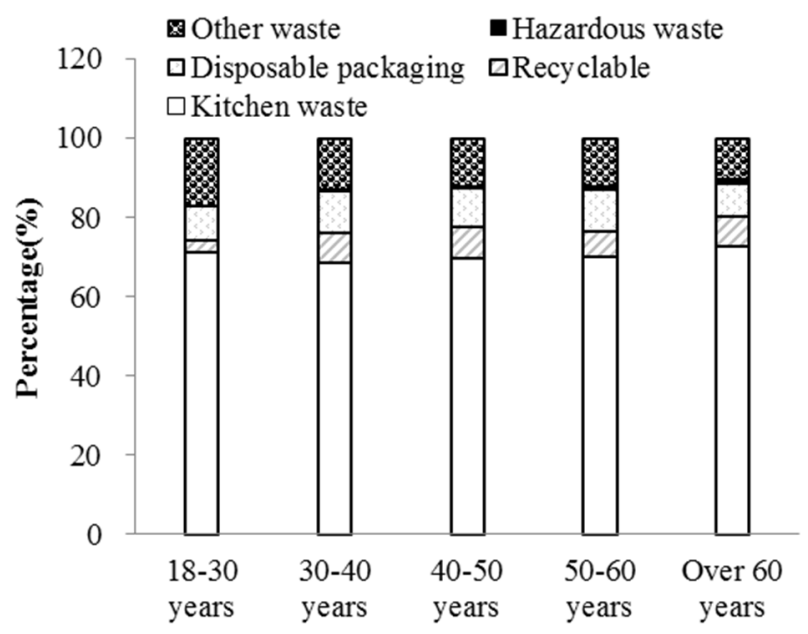

Fig. 2. Physical composition of MSW in different average ages of family

\subsection{The effect of educational background on the components of MSW}

The Fig. 3 showed the physical composition of MSW in different families with different educational backgrounds. It can be seen that with the increase of education, the proportion of kitchen waste decreased from $73 \%$ to $66 \%$, while the contents of recyclables and disposable packaging showed a slow upward trend. Plastic and glass were the main components of the recyclables, both of which account for $30 \%$ of the total recoverable materials. Plastic was the main components of the disposable packaging, accounting for $74 \%$ to $87 \%$ of the total disposable packaging. The change of educational background of family had little impact on harmful waste and other waste. The proportion of harmful waste in MSW was between $0 \%$ and $1 \%$.

\subsection{Effect of family building area on the components of MSW}

The physical composition of MSW in different families with different building area was shown in Fig. 4. The proportion of the kitchen waste in MSW decreased at first and then increased with the increase of building area of the family. When the building area of the family was increased from 50 square meters to 150 square meters, the content of the kitchen waste was reduced from $73 \%$ to $68 \%$. When the building area was further increased to more than 200 square meters, the content of kitchen waste increased to $77 \%$. The 50 square meters was used as a dividing point for the residential area of the family, the proportion of disposable packaging and other waste in MSW increased at first and then decreased with the increased of building area. The building area of the family had little effect on the proportion of harmful waste. 


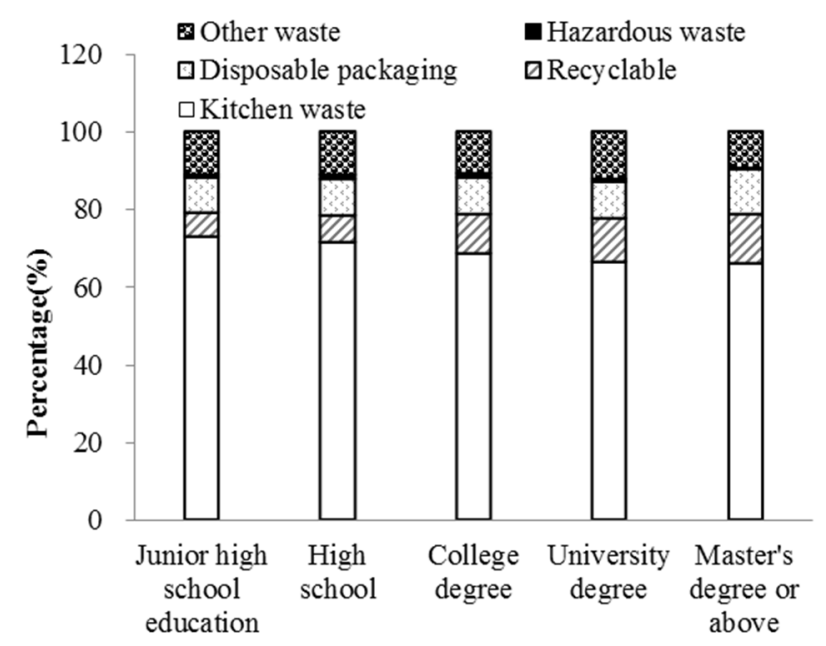

Fig. 3. Physical composition of MSW in different educational background of family

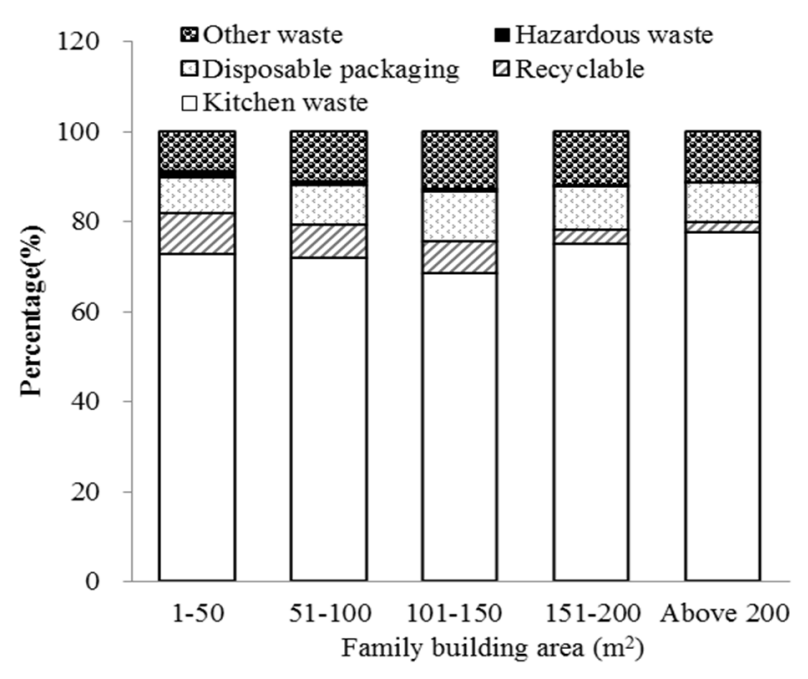

Fig. 4. Physical composition of MSW in different family building area

\subsection{Effect of family income on the components of MSW}

It can be seen from Fig. 5 that the proportion of kitchen waste was slowly decreasing with the increase of income. When the monthly household income increased from 2000 RMB to 30, $000 \mathrm{RMB}$, the content of kitchen waste decreased about $24 \%$. In contrast, the proportion of recyclable material increased obviously with the increase of income. The content of recyclable had increased by about three times, when the income increased from 2000 RMB to 30, 000 RMB. It was worth noting that paper and glass were the main components of the recyclable, both accounting for $56-72 \%$ of the total recyclable material. Therefore, it was necessary to strengthen the collection of recyclable materials and improve the temporary storage capacity of recyclable materials in high-grade residential areas.

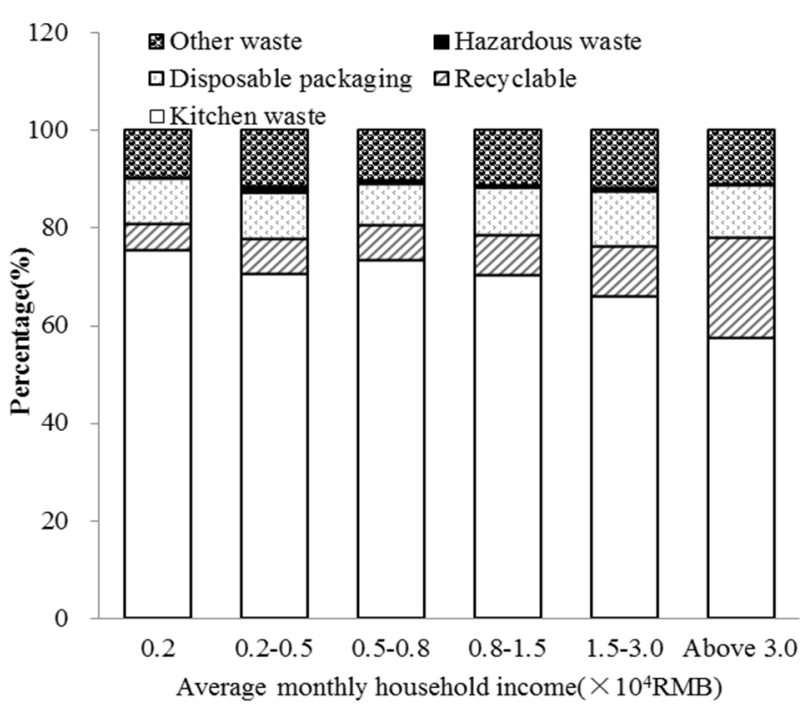

Fig. 5. Physical composition of MSW in different family with different income level

\section{Conclusions}

(1)The composition of MSW in four seasons was similar, and the kitchen was the main composition of MSW. The proportion of kitchen waste was between $69 \%$ and $74 \%$ in the four seasons. The second category of MSW was other waste, accounting for $10-20 \%$ of the total amount of MSW. Therefore, the key to the management of MSW was to collect and dispose the kitchen waste and other waste.

(2)The average age of families had a great influence on the proportion of harmful waste and other waste in MSW. As the average age of the family increased, the proportion of other wastes was gradually reduced, and the proportion of the harmful waste was increased.

(3)The educational backgrounds and family income had a great influence on the proportion of kitchen waste and recyclables in MSW. With the increase of family educational backgrounds and family income, the content of kitchen waste decreased, while the content of recyclable waste increased obviously.

(4)The effect of family building area on the physical composition of MSW was different from other factors. The 50 square meters was used as a dividing point for the residential area of the family, the kitchen waste decreased at first and then increased, while the proportion of disposable packaging and other waste in MSW increased at first and then decreased with the increased of building area.

\section{Acknowledgements}

This study was financially supported by the Beijing Municipal Management Committee project "Investigation and prediction analysis of municipal solid waste generation in Beijing 2019". 


\section{References}

1. H. Cheng, Y. Hu. Bioresour. Technol., 101 (2010).

2. A.M. Troschinetz, J.R. Mihelcic. Waste Manage. 29(2009).

3. A. Magrinho, V. Semiao. Waste Manage. 28(2008).

4. S.J. Burnley. Waste Manageme. 27(2007).

5. W.G. Peng, J.B. He, Q.J. Yao, Z.M. Han, J.J. An, K.Q.Liu, Y. Tang. Environ. Sanitition Engineering, 22(2014)

6. E. Gidarakos, G. Havas, P. Ntzamilis. Waste Manage. 26(2006).
7. W.W. Wu, W. Wang. Urban Manage. and Sci. and Technol. 4(2002).

8. X.D. Dong, S.X. Xia, X.Y. Li. Environ. Sanitition Engineering, 23(2013).

9. R.C. Dong, Z.B. Ding, H.N. Guo. Environ. Sanitition Engineering, 26(2018).

10. G.Q. Wang, H.Y. Zhang, D. Wang, L. Zhang, W. Sun. Environ. Engineering, 36(2018).

11. C.F. Huang. Hua zhong Univ. of Sci. \& Technol. 2012. 